\title{
A Male with Hereditary Multiple Osteochondromas, Low Bone Mineral Density and Hashimoto’s Disease
}

\author{
Haider M Al Attia* \\ Department of Internal Medicine \& Rheumatology, Private practice, UAE \\ *Corresponding author: Haider M Al Attia, Consultant in Internal Medicine and \\ Rheumatology, Private practice, Abu Dhabi, UAE. PO Box 60420, Tel: 506137795; \\ Email: haideralattia@hotmail.com
}

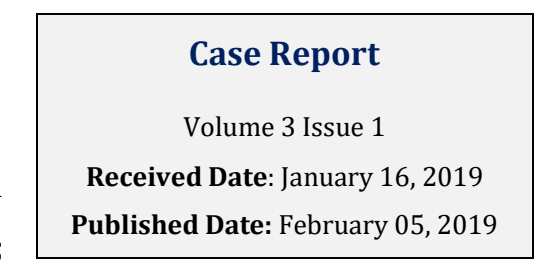

\begin{abstract}
A 36-year old male with multiple and deforming bony swellings due to hereditary multiple osteochondromas (HMO) was also found to have osteoporosis /osteopenia on DEXA scanning. The patient exhibited a non-clinical Hashimoto's disease as well. This report briefly projects on aspects related to the pathogenesis of the low bone density in this rare condition.
\end{abstract}

Keywords: Hereditary Multiple Osteochondromas; Exostosis; Osteoarthrosis; Osteochondrosarcoma

Abbreviations: HMO: Hereditary Multiple Osteochondromas; HME: Hereditary Multiple Exostoses; DEXA: Dual Energy X-ray Absorptiometry; BMD: Bone Mineral Density; BMI: Body Mass Index; ESR: Erythrocyte Sedimentation Rate; LFT: Liver Function Test; CCP: Cyclic Citrullinated Peptides; TPO: Thyroid Peroxidase Test.

\section{Introduction}

The disorder hereditary multiple osteochondromas (HMO), previously called hereditary multiple exostoses (HME), is characterized by growths of multiple cartilagecapped bone tumors that grow outward from the metaphysis of long bones The condition is manifested by a reduction in skeletal growth, bony deformity, restricted joint motion, shortened stature, premature osteoarthrosis, and compression of peripheral nerves. Though, the risk for malignant degeneration to osteochondrosarcoma increases with age the lifetime risk of such malignant degeneration is low $(\sim 1 \%)$.

The diagnosis of HMO is based on clinical and/or radiographic findings of multiple exostosis in one or more members of a family. Two genes in which pathogenic variants are known to cause HMO are the EXT1 and EXT2. A combination of sequence and deletion analysis of the entire coding regions of both EXT1 and EXT2 detects pathogenic variants in 70\%-95\% of affected individuals [1].

\section{Case Report}

A 36-year old Indian clerk with deformities in the form of bilateral swellings and pain in the limbs. His deceased mother had similar deformities, but other 3 siblings were not affected. His height was $163 \mathrm{~cm}$, weight of $61 \mathrm{~kg}$ and BMI of 22. CBC, ESR, urea \& creatinine, LFT, serum Iron, B12, LH, FSH, RF, and anti CCP Abs were within normal values. The $25(\mathrm{OH}) \mathrm{D}$ was $23 \mathrm{ng} / \mathrm{ml}(\mathrm{N},>30 \mathrm{ng} / \mathrm{ml})$, serum Ca $8.9 \mathrm{mg} / \mathrm{dl}$ (N, 8.4-10.5mg/dl), Ionized Ca $1.133 \mathrm{mmol} / \mathrm{L}$ $(\mathrm{N}, 1.16-1.32 \mathrm{mmol}) \& \mathrm{PTH}$ of $69.64 \mathrm{p} \mathrm{g} / \mathrm{ml}(\mathrm{N}, 15-$ $65 \mathrm{pg} / \mathrm{ml}$ ). Thyroid function tests (FT3, FT4 \& TSH) were within normal values, yet the antithyroid peroxidase antibodies titer (TPO) Abs titer was elevated (227.9 IU/ml. $\mathrm{N},<35)$ indicating a biochemical Hashimoto thyroiditis. Serum osteocalcin was low $(6.02 \mathrm{ng} / \mathrm{ml}, \mathrm{N}, 9-42 \mathrm{ng} / \mathrm{ml})$ but the Beta-Cross Laps (Beta -CTx) in serum was within normal values of $190 \mathrm{pg} / \mathrm{ml}(\mathrm{N}, 90-630 \mathrm{pg} / \mathrm{ml})$. 


\section{Clinical Radiology \& Imaging Journal}

The DEXA scan using the Z-score showed osteoporotic values in both femurs (-4.1 in Left and -3.1 in Right) and osteopenic score of -1.7 in the spine. The radiology profile shown below (Figure 1) is demonstrating the osteochondromas of the upper and lower limbs and spinal scoliosis along with limbs deformities. He was treated with bisphosphonate and vitamin D supplementation. Unfortunately, he was lost to follow up.

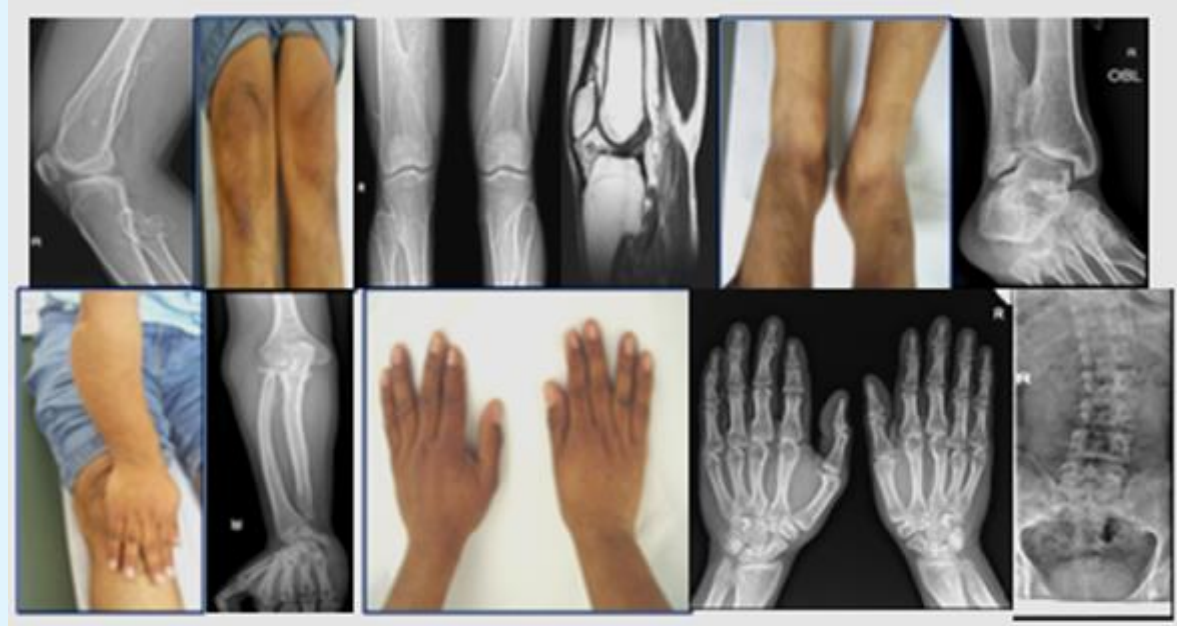

Figure 1: Pictorial and radiological (X-ray and MRI images) of the patient showing the various affected skeletal sites along with the spinal scoliosis.

\section{Discussion}

A previous work revealed a novel heterozygous acceptor splice site mutation of EXT1 results in hereditary multiple exostosis that is associated with low bone mass , indicating a possible additional role for EXT1 in bone biology and in regulating BMD [2]. We assume this patient with evidently strong FH of HMO would fit within the above conclusion. Nonetheless, he also had hypovitaminosis D and mild secondary hyperparathyroidism which might have contributed further to the low BMD. Thyroid hormones are also known to be necessary for the development and function of bone. This is visible in conditions of hyperthyroidism including primary (overt or subclinical) or iatrogenic forms in inducing decreased bone density. Hypothyroidism on the other hand seems to have controversial influence on bone metabolism but probably leads to increased fracture risk [3]. Our patient was euthyroid clinically and biochemically therefore his thyroid status could not be implicated for the low bone density. Nonetheless, a strict and regular follow up to monitor the thyroid function would be imperative in his case.

\section{Conclusion}

Therefore at the diagnosis of this uncommon skeletal disorder, it would be equally important to pay attention to the bone mineral status, vitamin D level and perhaps to the thyroid function as well.

Acknowledgment: Thanks to Mr Mohamed Abu Shawish for his assistance in this work.

\section{References}

1. Wuyts W, Schmale GA, Chansky HA, Raskind WH (2000) Hereditary Multiple Osteochondromas. In: Pagon RA, et al. University of Washington, Seattle; 1993-2014.

2. Lemos MC, Kotanko P, Christie PT, Harding B, Javor T, et al. (2005) A novel EXT1 splice site mutation in a kindred with hereditary multiple exostosis and osteoporosis. J Clin Endocrinol Metab 90(9): 53865392.

3. Tuchendler D, Bolanowski M (2014) The influence of thyroid dysfunction on bone metabolism. Thyroid Res 7: 12 . 